\title{
Comparative Evaluation between Tympanoplasty Alone \& Tympanoplasty Combined With Cortical Mastoidectomy in Non- Cholesteatomatous Chronic Suppurative Otitis Media in Patients with Sclerotic Bone
}

\author{
Manpreet Kaur, Baldev Singh, B.S. Verma, Gurpreet Kaur, Gaurav Kataria, \\ Savijot Singh, Parul Kansal, Bhavna Bhatia
}

\begin{abstract}
Objectives: To compare the results of tympanoplasty alone and tympanoplasty with cortical mastoidectomy in chronic suppurative otitis media (CSOM) patients with sclerotic bone in terms of graft uptake, perforation closure, improvement in hearing and disease eradication.

Study Design: Retrospective study of patients at tertiary referral hospital.

Method: 50 cases of non-cholesteatomatous chronic suppurative otitis media were selected. Tympanoplasty alone was done in 25 cases and tympanoplasty combined with cortical mastoidectomy was done in another 25 cases. Patients were reviewed postoperatively at 4,8 and 12 weeks to inspect the operated ear for graft uptake or any complication. Pure tone audiometry (PTA) was done at $2^{\text {nd }}$ and $4^{\text {th }}$ month to evaluate the hearing improvement.

Results: In our study, hearing gain in decibel $(d B)$ in tympanoplasty group was 7.64 and in tympanoplasty combined with cortical mastoidectomy was 8.84 . Graft uptake was $76 \%$ in tympanoplasty group and $88 \%$ in tympanoplasty combined with cortical mastoidectomy. Recurrence of discharge was seen in 2 cases of tympanoplasty. Though tympanoplasty combined with cortical mastoidectomy is better in hearing improvement, graft uptake and clinical improvement but the difference in 2 groups is statistically insignificant.

Conclusion: Hearing improvement, graft uptake and clinical improvement were statistically incomparable in 2 groups. Combining cortical mastoidectomy with tympanoplasty will not give additional benefits in terms of hearing gain, disease clearance and graft uptake.
\end{abstract}

Keywords: chronic suppurative otitis media, tympanoplasty, cortical mastoidectomy, pure tone audiometry.

\section{Introduction}

Among the various causes of ear diseases, chronic suppurative otitis media is the major disorder in our country. It is the chronic inflammation of the middle ear cleft which is composed of Eustachian tube, hypotympanum, mesotympanum, epitympanum, aditus and mastoid air cells which presents with recurrent ear discharge through tympanicperforation. ${ }^{[1]}$ Clinically CSOM is of two types- tubotympanic type and atticoantral type. Continuing mucosal infection of the middle ear by resistant organisms, continuing infection of the nasopharynx with secondary infection of the middle ear cleft and changes in the mucosa of the middle ear secondary to eustachian tube dysfunction may all contribute to the development of chronic otitis media. ${ }^{[2]}$ The WHO definition requires only two weeks of otorrhoea ${ }^{[3]}$ but otolaryngologists tend to adopt a longer duration e.g. more than three months of active disease. ${ }^{[4]}$ In India, prevalence rate is $7.8 \%$ which is very high. In Britain, $0.9 \%$ of children \& $0.5 \%$ of adults have CSOM with no difference between the sexes. ${ }^{[5]}$ Worldwide, there are between 65-330 million sufferers.

Standard treatment of CSOM is conservative management with aural toilet, topical antibiotics, systemic antibiotics and dry ear precautions. ${ }^{[6]}$

In those that do not resolve or do not result in spontaneous healing of tympanic membrane with conservative measures, surgical intervention is done. Surgical intervention for safe / tubotympanic / Non cholesteatomatous CSOM is tympanoplasty. ${ }^{[7]}$

The two opposing demands of tympanoplasty namely to eradicate the disease and at the same phase trying to maintain as much normal tissue as possible to facilitate reconstruction of hearing mechanism is a demanding task.

Mastoid plays an important role in middle ear aeration and pressure regulation. There has been a clinical impression that lack of an aerating mastoidectomy at the time of the initial tympanoplasty may be a significant source of failure in patients with chronic non-cholesteatomatous otitis media so cortical mastoidectomy along with tympanoplasty has for long been considered the surgical procedure of choice. ${ }^{[8]}$ 
In the present study with available resources at Government Medical College and Rajindra Hospital, Patiala, the aim of our study was to compare the effects of tympanoplasty versus tympanoplasty combined with cortical mastoidectomy done for tubotympanic or non-cholesteatomatous type of CSOM with sclerotic mastoids.

\section{Aims And Objectives}

Present study was undertaken to evaluate the comparison between tympanoplasty alone and tympanoplasty with cortical mastoidectomy in CSOM patients with sclerotic bone in terms of:

1. Graft uptake and perforation closure.

2. Improvement in hearing and disease eradication.

\section{Material And Methods}

This retrospective study was conducted in the Ear, Nose and Throat Out Patient Department of Government Medical College and Rajindra Hospital, Patiala from 2010 to 2012. Total numbers of 50 patients were taken in the study. Inclusion criteria were central perforation with sclerotic bone, minimum of four weeks elapsed since last episode of ear discharge, mild to moderate conductive hearing loss, normal cochlear functions, good eustachian tube function and no evidence of infection in nose, paranasal sinuses, nasopharynx and throat. Patients having granulation tissue, cholesteatoma or polyp in the ear prior to surgery, any ossicular pathology as evidenced by PTA and intra operative evaluation, multiple tympanic membrane perforations, total or marginal perforation of pars tensa, complications of otitis media, patients aged below 12 years, mixed hearing loss and moderate to severe degree of hearing loss were excluded.

The patients were randomized into 2 groups and each group comprised of 25 patients. The group I patients underwent tympanoplasty and group II patients underwent cortical mastoidectomy with tympanoplasty. Detailed history, clinical examination including tuning fork test, pure tone audiometry was done to assess the quality and quantity of hearing loss. Examination under microscope was done to see the margins of the perforation, granulation tissue and polyp and the status of ossicular chain. Routine and radiological investigations including X-ray both mastoids (Law's lateral oblique view), High Resolution Computed Tomography Scan both mastoids, X-ray soft tissue nasopharynx lateral view to rule out adenoid enlargement and X-ray paranasal sinuses (Water's view). Any infection of sinuses, tonsils or adenoids was treated. End point of the study was considered by two points, first, dry ear with graft uptake at the end of four months, and second, post-operative hearing improvement. Data obtained was analyzed according to Chi square test and Student't' test.

\section{Observations}

The present study consisted of 50 patients. 25 patients underwent tympanoplasty alone and another 25 underwent tympanoplasty combined with cortical mastoidectomy in non-cholesteatomatous CSOM with sclerotic mastoids. Study was done to know the need of mastoidectomy in safe CSOM to form the common consensus regarding its surgical management.

\section{Statistical Basis Of Study}

For comparing non-parametric data-Chi square test.

For comparing means-Student' $t$ ' test.

Non-parametric data included gender, rural-urban distribution, side taken up for surgery, laterality, size of perforation, degree of hearing loss, anesthesia given ,clinical improvement in terms of ear discharge and graft uptake.Means included age distribution, duration of discharge, duration of dryness and hearing gain.

Table I- Age distribution of patients

\begin{tabular}{|l|l|l|l|l|}
\hline \multirow{3}{*}{ Age in years } & Tympanoplasty & \multicolumn{2}{l|}{ Tympanoplasty with cortical mastoidectomy } \\
\cline { 2 - 5 } & No. & $\%$ & No. & $\%$ \\
\hline $12-19$ & 3 & 12 & 5 & 20 \\
\hline $20-29$ & 13 & 52 & 11 & 44 \\
\hline $30-39$ & 5 & 20 & 6 & 24 \\
\hline $40-49$ & 4 & 16 & 3 & 12 \\
\hline Total & 25 & 100 & 25 & 100 \\
\hline Mean and std deviation & $30.04 \pm 8.84$ & $26.64 \pm 9.101$ & \\
\hline
\end{tabular}

Both groups were comparable with $\mathrm{p}=0.187$. Patients aged between 20 - 29 were more in the study group i.e., 24 patients(48\%). 11 (22\%) patients were found in the age group of 30-39 years.8(16\%) patients in 12-19 age group and 7(14\%) patients in 40-49 age group.

Samples were age matched with $\mathrm{p}=0.187$. 
Females were more in the study group. 13 patients (52\%) in mastoidectomy group and 15 patients $(60 \%)$ in without mastoidectomy group. Gender distribution was found to be statistically similar with $\mathrm{p}=0.569$. Left sided ear was affected in 29 cases (58\%) and right side was affected in 21 cases (42\%).Side taken up for surgery in both groups was found to be statistically similar with $\mathrm{p}=0.774$.

Table II -Duration of ear discharge (in years)

\begin{tabular}{|l|l|l|l|l|}
\hline \multirow{2}{*}{ Duration of discharge } & \multicolumn{2}{|l|}{ Tympanoplasty } & \multicolumn{2}{c|}{$\begin{array}{l}\text { Tympanoplasty with } \\
\text { mastoidectomy }\end{array}$} \\
\cline { 2 - 5 } & No. & $\%$ & No. & $\%$ \\
\hline$<1$ year & 2 & 8 & 2 & 40 \\
\hline $1-5$ years & 14 & 56 & 10 & 28 \\
\hline 6-10 years & 3 & 12 & 7 & 24 \\
\hline$>10$ years & 6 & 24 & 6 & 100 \\
\hline Total & 25 & 100 & 25 & $10.560 \pm 10.6138$ \\
\hline Mean and std deviation & $7.437 \pm 7.8550$ & & & \\
\hline
\end{tabular}

Difference in the duration of ear discharge in both the groups was not significant hence incomparable with $\mathrm{p}=0.243$.

Table III-Duration of dryness of the ear to be operated (in months)

\begin{tabular}{|l|l|l|l|l|}
\hline \multirow{2}{*}{ Duration of dryness } & \multicolumn{2}{|l|}{ Tympanoplasty } & \multicolumn{2}{l|}{ Tympanoplasty with cortical mastoidectomy } \\
\cline { 2 - 5 } & No. & $\%$ & No. & $\%$ \\
\hline $1-3$ months & 13 & 52 & 14 & 56 \\
\hline $4-6$ months & 9 & 36 & 10 & 40 \\
\hline$>6$ months & 3 & 12 & 1 & 4 \\
\hline Total and std & 25 & 100 & 25 & 100 \\
\hline $\begin{array}{l}\text { Mean } \\
\text { deviation }\end{array}$ & $3.96 \pm 2.638$ & $3.48 \pm 1.71$ \\
\hline
\end{tabular}

Difference in both the groups was found to be statistically insignificant as the $p$ value is 0.449 .

$X^{2}=2.914$

Table IV- Degree of hearing loss

\begin{tabular}{|l|l|l|l|l|}
\hline \multirow{2}{*}{ Degree of hearing loss } & \multicolumn{3}{|l|}{ Tympanoplasty } & \multicolumn{2}{l|}{ Tympanoplasty with cortical mastoidectomy } \\
\cline { 2 - 5 } & No. & $\%$ & No. & $\%$ \\
\hline Mild & 22 & 88 & 17 & 68 \\
\hline Moderate & 3 & 12 & 8 & 32 \\
\hline Total & 25 & 100 & 25 & 100 \\
\hline
\end{tabular}

Degree of hearing loss in both the groups was statistically similar with $\mathrm{p}=0.088$.

Table V-Size of perforation

\begin{tabular}{|c|c|c|c|c|}
\hline \multirow{2}{*}{ Size of perforation } & \multicolumn{2}{|c|}{ Tympanoplasty } & \multicolumn{2}{|c|}{ Tympanoplasty with cortical mastoidectomy } \\
\hline & No. & $\%$ & No. & $\%$ \\
\hline Small & 7 & 28 & 5 & 20 \\
\hline Medium & 10 & 40 & 10 & 40 \\
\hline Large & 6 & 24 & 6 & 24 \\
\hline Subtotal & 2 & 8 & 4 & 16 \\
\hline Total & 25 & 100 & 25 & 100 \\
\hline
\end{tabular}

$\mathrm{X}^{2}=1.000 \quad \mathrm{p}=0.801$

Size of perforation was statistically insignificant in both the groups with $\mathrm{p}=0.801$.

Table VI-Graft take up status after surgery

\begin{tabular}{|l|l|l|l|l|}
\hline \multirow{2}{*}{ Graft status } & \multicolumn{2}{|l|}{ Tympanoplasty } & \multicolumn{2}{l|}{ Tympanoplasty with cortical mastoidectomy } \\
\cline { 2 - 5 } & No. & $\%$ & No. & $\%$ \\
\hline Graft taken & 19 & 76 & 22 & 88 \\
\hline Not taken & 6 & 24 & 3 & 12 \\
\hline Total & 25 & 100 & 25 & 100 \\
\hline
\end{tabular}

$\mathrm{X}^{2}=1.220 \quad$ Graft take up status was statistically similar in both the groups with $\mathrm{p}=0.269$. 
Comparative Evaluation Between Tympanoplasty Alone \& Tympanoplasty Combined With ...

Table VII-Clinical improvement after surgery

\begin{tabular}{|l|l|l|l|l|}
\hline \multirow{2}{*}{ Clinical improvement } & Tympanoplasty & \multicolumn{3}{l|}{ Tympanoplasty with cortical mastoidectomy } \\
\cline { 2 - 5 } & No. & $\%$ & No. & $\%$ \\
\hline Ear Discharge + & 2 & 8 & 0 & 100 \\
\hline Ear Discharge - & 23 & 92 & 25 & 100 \\
\hline Total & 25 & 100 & 25 & \\
\hline
\end{tabular}

$\mathrm{X}^{2}=2.083$

Clinical improvement after surgery in terms of recurrence of ear discharge was found to be statistically insignificant in both groups with $\mathrm{p}=0.149$.

Table VIII-Audiological assessment (In dB)

\begin{tabular}{|c|c|c|c|c|c|}
\hline \multirow{2}{*}{$\begin{array}{l}\text { Audiological } \\
\text { assessment }\end{array}$} & \multicolumn{2}{|c|}{ Tympanoplasty } & \multicolumn{2}{|c|}{ Tympanoplasty with cortical mastoidectomy } & \multirow{2}{*}{$P$ value } \\
\hline & Mean & Std deviation & Mean & Std deviation & \\
\hline Pre-op hearing loss & 35.44 & 6.862 & 36.96 & 7.348 & .465 \\
\hline PTA at $2^{\text {nd }}$ month & 30.72 & 6.413 & 31.48 & 6.104 & .670 \\
\hline PTA at $4^{\text {th }}$ month & 27.72 & 7.197 & 27.88 & 5.967 & .932 \\
\hline Benefit & 7.64 & 5.787 & 8.84 & 5.129 & .442 \\
\hline
\end{tabular}

In tympanoplasty group, benefit in $\mathrm{dB}$ in PTA pre-operatively and 4 months after surgery was 7.64 and in tympanoplasty with cortical mastoidectomy, it was 8.84. Though it was slightly more in slightly more in latter but difference was statistically insignificant. Hearing gain was matched with $\mathrm{p}=0.442$.

\section{Discussion}

In the present study, the cases selected were between 12- 50 years. Patients aged between 20- 29 were more in the study group i.e. 24 patients (48\%), 11 (22\%) patients were found in the age group of 30-39 years, $8(16 \%)$ in 12-19 age group and 7(14\%) patients in 40-49 age group. In a study conducted by Lasisi and Afolabi $(2008)^{[9]}$ the majority of patients were aged 21-34 years which was in concurrence with present study. In the present study, 33 patients had rural background and 17 patients had urban background which could be due to the lack of awareness about the disease, its sequelae and lack of proper referral to specialized centres.

In present study, out of 50 patients, 4 had ear discharge for less than 1 year, 24 had for 1-5 years, 10 patients had for 6-10 years and 12 patients had discharge for more than 10 years. In a study by Varshney et al $(2010)^{[10]}$,duration of discharge varied from 6 months to 50 years with 26 patients having duration of discharge ranging from 1-5 years which was comparable with the present study.

In our study, Period of dryness is 1-3 months in 13 patients, $4-6$ months in 9 patients and more than 6 months in 3 patients in group I .14 patients in group II had 1-3 months duration of dryness, 10 had 4-6 months and 1 patient had more than 6 months duration of dryness. As per study done by Armstrong and Charlotte $(1965)^{[11]}$ dry ear is must in children before doing tympanoplasty.

Small central perforation was seen in 12 patients (24\%), medium sized perforation was found in 20 (40\%) patients and large central perforation was seen in12 (24\%) and subtotal perforation was seen in $6(12 \%)$ patients. In a study by Biswas et al (2010) ${ }^{[12]}$ medium sized perforation was commonest one which was also seen in the present study.

In our study, left sided ear was found to be affected in 29 cases (58\%) and right side was affected in 21 cases $(42 \%)$. This side predominance could not be explained, since majority of them were right handed persons and ear picking as a cause could not be attributed to the side predominance. In a study done by Nagle et al $(2009)^{[13]}$ the perforation was more commonly found on the right side which was in contrast to our study.

In our study, graft uptake rate was $76 \%$ in group I and $88 \%$ in group II. Though the graft uptake was more in group II but the difference in both the groups was statistically insignificant. In our study, ear discharge occurred only in 2 cases in group I while in group II, no case on follow up was reported to have ear discharge. But as p value was 0.149 so difference was statistically insignificant. In our study, in group I, benefit in $\mathrm{dB}$ in pure tone threshold pre-operatively and 4 months after surgery was 7.64 and in group II it was 8.84.Though it was slightly more in latter but difference was statistically insignificant.

In study by Krishnan et al (2002) ${ }^{[14]}$ post-operative hearing gain was $75 \%$ in both groups. Similarly, Balyan et al (1997) ${ }^{[15]}$ in a study conducted on 48 patients with CSOM, treated by means of tympanoplasty with and without mastoidectomy found no significant difference in graft failure rates or hearing results. They also concurred that the addition of mastoidectomy had increased effort and risk to the surgery.

In a study done by Toros et al (2010) ${ }^{[16]}$ tympanic membrane perforation closure was successful in $76.1 \%$ of the 46 patients undergoing Myringoplasty and in $78.3 \%(\mathrm{n}=36)$ of the 46 patients undergoing Myringoplasty with mastoidectomy. The difference was not statistically significant $(\mathrm{p}>0.05)$. The difference between the two groups for hearing gain was also not statistically significant $(p>0.05)$ 
Mishiro et al (2009) ${ }^{[17]}$ also supported the use of tympanoplasty without mastoidectomy in chronic noncholesteatomatous otitis media with an equivalent rate of grafting success and hearing results regardless of the state of the ear at repair (draining vs. nondraining) or the addition of a mastoidectomy.

A study by McGrew et al (2004) ${ }^{[18]}$ examined the effect of mastoidectomy with canal wall up on 484 dry, post infectious, unoperated, noncholesteatomatous TM perforations v/s tympanoplasty alone and showed identical perforation closure success rates of $91 \%$ in each group. Hearing results were also statistically insignificant.

In contrast to our study, a study conducted by Holmquist and Bergstrom $(1978)^{[19]}$ suggested that mastoidectomy improves the chance of successful tympanoplasty for patients with noncholesteatomatous chronic otitis media.

In a study conducted by Nayak et al $(2003)^{[20]}$ of a sample size of 40 patients which were followed up for a period of 20.4 months had a success rate of $100 \%$ in MTP and $60 \%$ in TP revealing that mastoidectomy is required in all cases.

Comparison chart showing studies done by various authors showing pre-operative and post-operative airbone gap:

\begin{tabular}{|l|l|l|l|l|l|}
\hline Author & \multicolumn{2}{|l|}{ Tympanoplasty } & \multicolumn{2}{l|}{ Tympanoplasty with cortical mastoidectomy } & P value \\
\hline & Pre-op A-B gap & Post-op A-B gap & Pre-op A-B gap & Post-op A-B gap & \\
\hline Balyan et al & 29.2 & 19.4 & 27.8 & 20.1 & $>.05$ \\
\hline Mcgrew et al & $34.1 \pm 19.5$ & $16.4 \pm 12.4$ & $25.8 \pm 13.6$ & $14.4 \pm 11.1$ & $>.05$ \\
\hline Toros et al & $21.04 \pm 8.43$ & $10.52 \pm 8.95$ & $26.44 \pm 10.03$ & $16.77 \pm 11.1$ & $>.763$ \\
\hline Our study & $35.44 \pm 6.862$ & $27.72 \pm 7.197$ & $36.96 \pm 7.348$ & $27.88 \pm 5.787$ & .932 \\
\hline
\end{tabular}

Comparison chart showing studies done by various authors showing graft uptake:

\begin{tabular}{|l|l|l|l|}
\hline \multirow{2}{*}{ Author } & Tympanoplasty & Tympanoplasty with cortical mastoidectomy & \multirow{2}{*}{ P value } \\
\cline { 2 - 4 } & Graft uptake & Graft uptake & $>.05$ \\
\hline Balyan et al & $89.2 \%(\mathrm{n}=242)$ & $85.7 \%(\mathrm{n}=28)$ & $>.05$ \\
\hline Mcgrew et al & $90.6 \%(\mathrm{n}=320)$ & $91.6 \%(\mathrm{n}=144)$ & .804 \\
\hline Toros et al & $76.1 \%(\mathrm{n}=46)$ & $78.3 \%(\mathrm{n}=46)$ & .269 \\
\hline Our study & $76 \%(\mathrm{n}=25)$ & $88 \%(\mathrm{n}=25)$ & \\
\hline
\end{tabular}

\section{Conclusion}

Hearing improvement, graft uptake and clinical improvement were found to be statistically incomparable in 2 groups. Combining cortical mastoidectomy with tympanoplasty will not give additional benefits in terms of hearing gain and disease clearance.

The factors influencing graft uptake, hearing and healing are better Eustachian tube function, age of patient, duration of disease, discharge free period, size of the perforation, and status of middle ear mucosa. Incidence of upper respiratory tract infection has adverse effect on healing and hearing outcome.

\section{Bibliography}

[1]. Jahn AF, Chronic otitis media: diagnosis and treatment. Med Clin North America, 1991,75(6),1227

[2]. Hall IS, Colman BH. Diseases of nose, throat, ear and head and neck, 13th ed.Edinburgh: Livingstone 1td; $1987 . p g$ 231.

[3]. Smith AW, Hatcher J, Mackenzie, Thompson S, and Bal J: Randomized control of CSOM in Kenyan school children. Lancet. 1996; 348:1128-1133.

[4]. Goycoolea MV, Hueb MM, Ruah C: Definitions and terminology. Otolaryngol Clin North America, 1991, 24(4); 757-76

[5]. Gleeson M.Scott-Brown's Otorhinolaryngology, Head and Neck Surgery. $7^{\text {th }}$ ed.London: Hodder Arnold; $2008 . p g .3396$.

[6]. Macfadyen CA, Acuin JM, Gamble C. Systemic versus topical antibiotic treatments for chronically discharging ears with underlying eardrum perforations. Cochrane Database Syst Rev. 2006 Jan 25.

[7]. Ruhl CM and Pensak ML: Role of aerating mastoidectomy in non cholesteatomatous CSOM. The Laryngoscope 1999 December, 109 (12); 1924-7.

[8]. Alper C.M, Kitsko D.J, Shwartz J.D, Martin B, Yuksel S, Cullen Doyle B.M,

[9]. Villardo R.J.M and Doyle W.J.Role of the mastoid in middle ear pressure regulation. The Laryngoscope 2011; vol.121:404-8.

[10]. Lasisi A.O \& Afolabi O.A; Mastoid surgery for chronic ear: A ten year review. The Internet journal of head and neck surgery2008; 2 (2).

[11]. Varshney S, Nangia A, Bist SS, Singh RK, Guptha N. Ossicular chain status in chronic suppurative otitis media in adults. Indian J Otolaryngolol Head Neck Surg.2010; 62(4): 421-426.

[12]. Armstrong BW and Charlotte NC: Tympanoplasty in children. The Laryngoscope 1965; 75:1062-69.

[13]. Biswas SS, Hossain MA, Alam MM, Atif MT, Amin ZA. Hearing evaluation after myringoplasty Bangladesh J Otorhinolaryngol 2010; 16(1): 23-28.

[14]. Nagle SK, Jagade MV, Gandhi SR and Pawar PV. Comparative study of outcome of type I tympanoplasty in dry and wet ear. Indian J Otolaryngol Head Neck Surg April-June 2009; 61:138-140.

[15]. Krishnan A, Reddy EK, Nalinesha KM, Jagannath PM: Tympanoplasty with or without cortical mastoidectomy-a comparative study, Indian Journal of Otolaryngology and Head and Neck Surgery.2002; 54(3): 195-198.

[16]. Balyan FR, Celikkanat S, Aslan A,Taibah A,Russo A,Sanna M. Mastoidectomy in non-cholesteatomatous CSOM - is it necessary? Otolaryngol Head and Neck 1997; 117(6):592-5. 
[17]. Toros SZ, Habesoglu TE, Habesglu M, Bolukbasi S, Naiboglu B, Karaca CT and Egele E: Do patients with sclerotic mastoids require aeration to improve the success of tympanoplasty? Acta Otolaryngol Supp. 2010 Aug; 130(8): 909-912.

[18]. Mishiro Y, Sakagami M, Takahashi Y et al: Long term outcomes after tympanoplasty with or without mastoidectomy for perforation in CSOM. Eur Arch OtorhinoLaryngol. 2009 Jun; 266 (6):819-22.

[19]. McGrew B.M., Jackson CG, Glasscock ME: Impact of mastoidectomy on simple tympanic membrane perforation. The Laryngoscope, 2004; 114 (3): 506-511.

[20]. Holmquist J and Bergstrom B. The mastoid air cell system in ear surgery. Arch Otolaryngology.1978; 104:127-9

[21]. Nayak DR, Balakrishnan R, Hazarika P, Mathew PT. Role of cortical mastoidectomy in the results of myringoplasty for dry tubotympanic disease. Indian Journal of Otology.2003; 9:11-5. 